\title{
Third Places and Art Spaces: Using Web Activity to Differentiate Cultural Dimensions of Entrepreneurship Across U.S. Regions
}

\author{
Timothy F. Slaper', Alyssa Bianco², Peter E. Lenz ${ }^{2}$ \\ ${ }^{1}$ Indiana Business Research Center, Indiana University, United States, ${ }^{2}$ Dstillery, United \\ States.
}

\begin{abstract}
We use unconventional, web-based user data to assess regional entrepreneurial activity and regional variations in characteristics and culture that drive differences in business formation. Using geographically granular, user-online activity to estimate a region's proclivity for entrepreneurship, we assess the statistical relationship between business formation, operationalized as establishment births, and a region's general interest in "third places" informal gathering and mixing locations - and websites related to arts, music and design - "arts spaces." We operationalize interest in, or intention to patronize, third places and arts spaces by individuals within a geographical unit of analysis (U.S. counties) who access website information and resources related to those third places. Controlling for regional interest in entrepreneurship related web resources, we find that interest in third places and art spaces is strongly associated with regional variation in business formation. This work corroborates research showing that regions with a high concentration of interest (and participation) in third places and art spaces may attract the attention of would be entrepreneurs as desirable places to live, work and explore business opportunities, and help identify and address a critical missing ingredient in regions that have lower rates of start-ups and business growth.
\end{abstract}

Keywords: entrepreneurship; business formation; website behavior; third places; regional culture. 


\section{Introduction}

User-based data on website visits raise the possibility of enabling researchers and policymakers to assess inter-regional differences in cultural attributes as they relate to economic performance, make economic data timelier and with greater geographic resolution.

The key contribution of this paper is to assess whether the web-user profile for interest in entrepreneurship, those interested in arts/design/music (ADM) and those visiting sites associated with third places (3P) like libraries and eating and drinking establishments are statistically related to business formation on a region by region basis. We make inferences that regional differences in these attributes may point to a population's culture as being more or less conducive to business formation and commercial innovation. We also confirm, or question, the degree to which various categories of ADM or 3P may have on business formation and innovation as often asserted by creative class and third places theories.

The paper is structured as follows. First, we highlight the touchstone literature relevant to our three interwoven strands of culture and entrepreneurship, nowcasting economic activity and 3P and ADM social theory. Second, we present our method and the unconventional data used. Third, we report the statistical results. Fourth, we conclude with a discussion about future research and possible policy applications.

\section{State of the Discussion}

Research on the potential of using the digital vapor trails, or digital exhaust, from tens of millions of users on tens of thousands of websites to predict economic outcomes, or nowcast economic activity, continues to grow. The often citied example is that of Glaeser et al. (2017) using online data sources, namely Yelp review data, to measure the critical economic activity of business formation well in advance of official government statistics. Other authors have joined the fray. Slaper and colleagues (2018a) linked interest in entrepreneurship related web resources with business formation for early start-up and growth phases of new ventures.

Two categories of regional attributes or characteristics may serve to fertilize the soil from which new businesses sprout: an arts and design concentration - often known as the creative class - and third places - meeting and mixing locations outside the home or work. Hawkins and Ryan (2013), for example, suggest that music festivals are a current form of third places for people and ideas to intermix and drive innovation. Creative class theory posits that there is a positive relationship between the arts and commercial innovation (Wojan and Nichols, 2018). Third places are also considered to provide a context and culture for the exchange of ideas and the coalescing of different types of talent needed to take an idea from the workbench to the market place (Oldenburg, 2001). Indeed, the Ewing Marion Kauffman Foundation developed the "1 Million Cups" initiative to provide space and resources 
designed to help entrepreneurs discover solutions and engage with their local constituencies over "a million cups of coffee."

Finally, these three threads can be seen integrating and advancing regionally specific cultural (or personality) characteristics, unconventional data (from personality profiles) and business formation (or entrepreneurship) in the work of Obschonka et al. (2015), who aligned regional personality trait concentrations with business formation. Our study makes three small steps forward. One, using behavioral data to signal a region's cultural and personality profile. Two, using granular geographical units of analysis. Three, using data on user revealed preferences that is collected daily to (potentially) monitor and evaluate policy outcomes in real time.

\section{Data and Method}

We operationalize entrepreneurship as the count of establishment births by county, as captured and reported by the Census Bureau. An establishment birth - the opening of a new place of business - may not be a start-up, but rather the result of a multi-location corporation expanding its service region. However, this data source is the most accurate, consistent and of longest duration of publically available datasets. As control variables, we include countybased data for educational attainment and the Economic Research Service continuum of urban to rural counties - nine categories from large, highly populated urban counties to low population density counties distant from urban areas. We include a variable from the U.S. Internal Revenue Service: county-level data on the proportion of tax returns indicating individuals who made investments in non-IRA, self-funded retirement accounts (in contrast to company sponsored retirement accounts) as a possible signal for entrepreneurs and small business owners. The remaining data are derived from ZIP code based data from dstillery llc and aggregated to a county total. The data/variable selections are based upon availability of data collected by dstillery llc according to their client needs, but include ADM profiles such as arts avocation, design occupations, architecture \& design occupations - variables used by Wojan \& Nichols (2018). Those variables not previously studied are profiles of people interested in live music as well as other $3 \mathrm{P}$ such as libraries, golf courses, and casual dining restaurants. Categorizing live music is difficult as the venues attracting the web traffic may be considered 3P (Hawkins \& Ryan, 2013), but the web traffic may also be those interested in the musical performance more than mixing with fellow audience members. Also included are the entrepreneurship web-resource user profile applied by Slaper and colleagues (2018a), as well as the previously unexplored venture capital occupation category and a small business resource profile. Lastly, two new potential 3P profiles/variables were included: one, "home brewers" who may have interest in micro-breweries and craft-beer third places; and two, volunteers at not-for-profit organizations. The latter can be strongly supported as both a third place for interpersonal mixing as well as an indicator of social capital. 
The distillery llc is a marketing analytics firm that enables transactions between website hosts and the advertisers that pay to make web-based content free and accessible to the public. The distillery llc captures behavior on the web for their clients to post targeted, customer-specific advertisements. The distillery llc creates an analytical category/profile based on a bundle of websites that pertain to a particular constituency. In this case, the constituencies of interest are current or future entrepreneurs and those interested in 3P and ADM. The dstillery generated ZIP code-based user/device profile concentration data that we aggregated into county geographic boundaries based on population proportions and for which there are data on establishment births and the control variables. In all, of all the 3110 U.S. counties, 3035 counties had complete data for all variables. We performed an OLS regression to estimate the relationship between the explanatory and control variables and the log of the count of establishment births between 2014 and 2016. Except for the control variables and the IRS personal retirement investment proportions, all variables are indexes of website access concentration by county, with an index value of 1.0 being the U.S. national average. These index values are multiples of a region's interest concentration and website access behavior. For example, if Region A has an index for entrepreneurship resources of 2.0 while Region B has an index of 4.0, devices in Region B are twice as likely to access entrepreneurship resources as Region A devices and four times as likely as the average U.S. device.

The dstillery llc data are very timely, while the most recent establishment births data are from 2016. (The 2016 Census Bureau's Statistics of U.S. Business data is the most current at the time of this writing.) That said, cultural factors and regional personality traits, like population characteristics, do not change quickly over time. This follows Obschonka et al. (2015) both in terms of a region's personality profile helping to explain regional entrepreneurial and business formation activity as well as the fact that the psychological cultural characteristics of a region take multiple years if not decades to change.

\section{Results}

The dstillery llc consumer profiles are based on topical interests and as individuals access web resources for information and engage in economic transactions, their web behavior reveals their vocations, avocations, commitments and intentions for future purchases and activities. Each user profile is scored as an index value that is a multiple of the U.S. average of one. This allows easy comparisons within a user-profile and between profiles in the model. A coefficient of 0.23 for venture capital occupations indicates that a one-unit change in the index is associated with a 23 percent change in establishment births, while a coefficient of 0.64 for entrepreneurship resources indicates that for each one-unit increase there is an associated 64 percent change in establishment births. (As caveats: these interpretations are correct for only small changes, and the range and skew of indexes may differ dramatically from one user profile to the next. A big three U.S. auto-maker has a normal bell distribution with a maximum index of 5.8 while an office share company maximum index is above 60 .) 
Table 1: Regression Results of Third Places and Art Spaces Influence on Business Formation.

Dependent Variable, county-based, Census Bureau

Log of Establishment Birth Counts

2014 to 2015 and 2015 to 2016

\begin{tabular}{|c|c|c|c|c|}
\hline Explanatory Variables, county-based, with data sources & Coefficients & $\begin{array}{l}\text { Standard } \\
\text { Error }\end{array}$ & t Stat & $P$-value \\
\hline $\begin{array}{l}\text { Educational Attainment: population with Bachelor's Degree, } \\
\text { percent - Census }\end{array}$ & 0.03 & 0.00 & 7.45 & 0.00 \\
\hline $\begin{array}{l}\text { Urban (1) to Rural (9) continuum - Economic Research Service } \\
\text { (USDA) }\end{array}$ & $(0.26)$ & 0.01 & $(28.14)$ & 0.00 \\
\hline $\begin{array}{l}\text { Tax filings with non-IRA individual retirement investments, } \\
\text { percent - IRS }\end{array}$ & 37.05 & 2.62 & 14.17 & 0.00 \\
\hline Entrepreneurship Resources user profile concentration $-d$ & 0.64 & 0.14 & 4.62 & 0.00 \\
\hline Live Music Interest user profile concentration $-\mathrm{d}$ & 0.43 & 0.06 & 7.64 & 0.00 \\
\hline Small Business Resources user profile concentration $-d$ & 0.61 & 0.09 & 6.60 & 0.00 \\
\hline Venture Capital Occupation user profile concentration $-\mathrm{d}$ & 0.23 & 0.06 & 4.02 & 0.00 \\
\hline Library Interest user profile concentration $-\mathrm{d}$ & $(0.53)$ & 0.05 & $(11.64)$ & 0.00 \\
\hline TGIFridays casual dining user profile concentration $-\mathrm{d}$ & 0.10 & 0.03 & 3.77 & 0.00 \\
\hline Buffalo Wild Wings casual dining user profile concentration - d & 0.03 & 0.03 & 1.09 & 0.28 \\
\hline Golf Course venues user profile concentration $-\mathrm{d}$ & 0.02 & 0.01 & 1.95 & 0.05 \\
\hline Arts Avocation user profile concentration - d & $(0.44)$ & 0.10 & $(4.17)$ & 0.00 \\
\hline Design Applications user profile concentration $-\mathrm{d}$ & 0.58 & 0.09 & 6.22 & 0.00 \\
\hline Architecture \& Design user profile concentration $-\mathrm{d}$ & $(0.14)$ & 0.07 & $(2.07)$ & 0.04 \\
\hline Volunteers serving in Non-Profit user profile concentration - d & 0.01 & 0.08 & 0.13 & 0.90 \\
\hline Home Brewing user profile concentration $-\mathrm{d}$ & $(0.56)$ & 0.05 & (11.51) & 0.00 \\
\hline Intercept & 4.80 & 0.10 & 47.91 & - \\
\hline
\end{tabular}

Adjusted R Square

0.73

\begin{tabular}{lcccc}
\hline & $d f$ & $S S$ & $M S$ & $\boldsymbol{F}$ \\
\hline Regression & 16.00 & $5,291.96$ & 330.75 & 513.43 \\
Residual & $3,036.00$ & $1,955.78$ & 0.64 & \\
Observations & 3,053 & & & \\
\hline
\end{tabular}

Source: $d=$ dstillery llc. 
The selected profile variables to represent ADM, 3P and entrepreneurship resource seekers were statistically robust. As reported in Table 1, the adjusted R-square was 0.73. Only the variables for the Buffalo Wild Wings, in contrast to the other casual dining third place, and non-profit volunteers were not statistically significant at 0.05 level. There were surprises, however, as several of the coefficients' direction and magnitude were in the opposite direction of expectations. Coefficients for home brewers, library, arts avocation, and architecture \& design profiles were negative. The home brewer profile, it appears, does not well represent those frequenting micro-brewery drinking establishments to socially mix but rather those aspiring to brew the craft beers served as such establishments. Libraries do not appear to be 3P for those starting new firms or older firms expanding their geographic reach. Considering the activities associated with libraries - finding information but not interacting and mixing with other patrons - absent special programs hosted at a library, these institutions are not well-suited for the exchange of ideas or making business contacts.

The more puzzling negative results are associated with arts avocation and architecture and design occupation profiles. It may well be that the live music profile is capturing the same statistical association with ADM as found by Slaper and colleagues (2018b) and Wojan and Nichols (2018). Live music performances may be reasonably categorized as either a third place or an ADM art space. Indeed, the profiles for arts avocation would include musicians and other performers, as well as artists and sculptors. Together, the magnitude and sign of the coefficients for arts avocation, design applications and architecture and design occupations tend to cancel one another, raising questions about whether third places and art spaces are complementary or whether one influence dominates.

The other statistical associations are in line with expectations: a positive relationship between educational achievement and business formation as well as the negative coefficient for the urban to rural spectrum that runs from one (dense-urban) to nine (sparse-rural). One would expect the rate of business formation to be scale dependent (urban), with greater populations, density and Jacobian interactions fostering higher rates of business formation together with higher levels of educational achievement.

\section{Conclusion}

We find support for the importance of third places and art spaces - as measured by a region's interest and, by extension, intention to participate in these pursuits - on business formation. Our study corroborates with the work of Obschonka and colleagues (2015) on the importance of regional culture on business dynamics, broadens the application of new sources of data to measure and monitor economic activity in almost real time in a manner similar to Glaeser and colleagues (2017), and strengthens the relevance of social theory regarding third places a'la Hawkins and Ryan (2013) and the creative class, e.g., McGranahan and Wojan (2007). 
These encouraging results warrant further exploration into developing sets of variables that more rigorously correspond with theories of economic and social outcomes as they relate to preferences and intentions as expressed by web behavior. Differentiating the beneficial influences of $3 \mathrm{P}$ in contrast to $\mathrm{ADM}$ would help secure the position of one theory over the other in terms of the strength of the effect on the exchange and synthesis of ideas and knowledge spillovers. Are the confluence venues and magnitude of social mixing more salient factors than the concentration of the creative class? Are there other regional cultural contours that may be currently unobserved that may reveal other important regional traits?

These unconventional and timely data have great promise to now-cast current economic activity or presage economic outcomes. These results, albeit early, show that there are regional cultural differences that may explain divergent outcomes of policies and initiatives designed to promote innovation and entrepreneurship. Researchers may be one step closer to identifying the scarce ingredient in a region's cultural context that constrains business dynamism. Supplementing that scarce ingredient would be a worthy pursuit for policymakers to encourage innovation, business dynamics, economic growth and social well-being.

\section{References}

Elmborg, J. K. (2011). Libraries as the spaces between us: Recognizing and valuing the third space. Reference \& User Services Quarterly, 338-350.

Glaeser, E. L., Kim, H., \& Luca, M. (2017). Nowcasting the local economy: Using yelp data to measure economic activity (No. w24010). National Bureau of Economic Research.

Hawkins, C. J., \& Ryan, L. A. J. (2013). Festival spaces as third places. Journal of place management and development.

McGranahan, D., \& Wojan, T. (2007). Recasting the creative class to examine growth processes in rural and urban counties. Regional studies, 41(2), 197-216.

Obschonka, M., Stuetzer, M., Gosling, S. D., Rentfrow, P. J., Lamb, M. E., Potter, J., \& Audretsch, D. B. (2015). Entrepreneurial regions: do macro-psychological cultural characteristics of regions help solve the "knowledge paradox" of economics?. PloS one, 10(6).

Oldenburg, R. (Ed.). (2001). Celebrating the third place: Inspiring stories about the great good places at the heart of our communities. Da Capo Press.

Slaper, T., Bianco, A., \& Lenz, P. (2018, September). Digital Vapor Trails: Using Website Behavior to Nowcast Entrepreneurial Activity. In 2nd International Conference on Advanced Reserach Methods and Analytics (CARMA 2018) (pp. 107-113). Editorial Universitat Politècnica de València.

Slaper, T., Wojan, T., Crown, D., \& Lenz, P. (2018b, November). Are the Problem Spaces of Economic Actors Increasingly Virtual? What Geo-located Web Activity Might Tell Us about Economic Dynamism. Presented at the North American Regional Science Council Annual Conference, San Antonio, TX.

Wojan, T. R., \& Nichols, B. (2018). Design, innovation, and rural creative places: Are the arts the cherry on top, or the secret sauce?. PloS one, 13(2). 